\title{
Authenticity and Contact Value
}

\author{
Joshua Lewis Thomas ${ }^{1} \mathbb{D}$
}

Accepted: 5 May 2021

(C) The Author(s) 2021

\section{Introduction}

In New York's Metropolitan Museum of Art, there is a small white marble torso - a fragment of a larger sculpture. The figure has no head and hence no expression, but the stylized, elongated arms gently folded over its stomach convey a sense of peacefulness. The information card attributes the statue to an unknown Cycladic artist, referred to only as the 'Goulandris Master', and provides little other information about the purpose or origin of the piece besides the fact that over four thousand years have passed between its carving and today. Despite this, even in its broken state, it remains a remarkably beautiful carving. What makes artefacts such as this so alluring? There are many factors. ${ }^{1}$ The figure in question is aesthetically attractive. It may also have scholarly value if it can teach us about past civilizations. Given people pay the ticket price to visit the MET's collection, it could well possess some economic value too. Though the society to which the statue belonged is gone, other objects like this might also retain some identity-based value if they remain relevant to certain surviving cultural or religious groups. Such objects might also possess some commemorative value, if they were designed to memorialize some event or person.

Yet, even if we strip away all these valuable features, there is a remainder - a kind of appeal to certain heritage objects which resists easy classification. Korsmeyer describes such things as having an 'aura', palpable to anyone who comes into their proximity. $^{2}$ This is because the targeted value does not arise from any obviously

\footnotetext{
${ }^{1}$ Traditionally, it has been acknowledged that cultural heritage can possess several forms of value. For a summary of some 20 more partly overlapping typologies, see Fredheim, L. Harald, and Khalaf, Manal, "The significance of values: heritage value typologies re-examined", International Journal of Heritage Studies, 22 (6), (2016): 466-481.

${ }^{2}$ Korsmeyer, Carolyn, Things: In Touch with the Past, (New York: OUP USA, 2019), p.12-15. Korsmeyer borrows the term 'aura' from Benjamin, Walter, "The Work of Art in the Age of Mechanical Reproduction," in Illuminations, Harry Zohn, trans., (New York: Harcourt, Brace, Jovanovich, 1968). Similarly to Korsmeyer, I will use the term 'aura' to pick out the value I am interested in, even if this constitutes a departure from Benjamin's original concept.
}

Joshua Lewis Thomas

joshlewisthomas@hotmail.co.uk

1 The Open University, Walton Hall, Milton Keynes MK7 6AA, UK 
perceptible properties, nor from any of the objects' potential uses. Rather it is a value that the object simply has or emanates and can be appreciated or enjoyed simply by being there with it. It is tempting to say, in such situations, that we value the marble statue not only because of its beauty, its educational use, or any of the other benefits it can provide, but simply in virtue of what it is - an object with its own specific identity and past.

Along with Korsmeyer, I believe this value is present in many archaeological artefacts, but also in historic sites. For example, Matthes describes how, standing at Gettysburg, "one can be overwhelmed with the weight of the bloody and momentous events that transpired there." 3 Similarly, Jones expresses how the painting of a mammoth at Pech-Merle caves offers a "mesmerising... encounter with both an extinct mammal and the mind that portrayed it."4 Again, both writers seem to be appreciating a distinct kind of aura-related value in these places which is not obviously reducible to, say, their educational or commemorative use. This value is often found in ancient sites or objects. Yet, as Korsmeyer notes, it can also seemingly arise in things which are not historically significant, such as "small, domestic items cherished only by individuals", family heirlooms, and meteor fragments which have fallen to earth. ${ }^{5}$

The aim of this paper is to identify and explain this mysterious valued quality. In section 1, I critically analyze one possible answer: that the value is conferred by the property of authenticity. Ultimately, I argue that this suggestion is not helpful as authenticity is best understood as a value-qualifier rather than a source of value in its own right. However, in section 2, I draw on some insights from both Korsmeyer and Matthes to develop a stronger account. Specifically, each theorist suggests that a key feature of the objects in question is their capacity to connect us to the past. Building on this, I argue that the aura-related value could arise in virtue of connections to essentially anything, provided those connections are ones we appreciate. Section 3 contains further development of this notion of 'contact value', and responses to some potential objections. Properly clarified, this mode of valuation can be used to explain the elusive appeal of the marble statue and historic sites as well as more mundane objects such as gifts, souvenirs, the possessions of celebrities, and ticketstubs. My account can also be expanded to explain the visceral revulsion we sometimes feel in the presence of certain objects or places with negative auras, and why we would typically prefer to engage with something like Hemingway's typewriter rather than his toothbrush.

\footnotetext{
3 Matthes, Erich Hatala, "History, Value, and Irreplaceability", Ethics, 124 (1), (2013): 35-64, p.65.

4 Jones, Jonathan, "Don't fall for a fake: the Chauvet cave art replica is nonsense", The Guardian, 15th April 2015.

5 op. cit. p.162, 69, 28.
} 


\section{Authenticity}

Here is a prima-facie plausible suggestion: the value-conferring property we are interested in is authenticity. It is easy to see how we might arrive at this conclusion. If we want to discover the source of the aura-related value, we ought to be able to identify the relevant property by isolating various features of the object, imagining they were missing, and assessing whether or not the object would lose its valued aura in virtue of that change. As hinted above, there do not appear to be any necessary relations between an object's aura and its directly perceptible qualities; the statue could be a different size, shape, color, or weight and still keep this mysterious characteristic. One change which would seem to make a difference, however, is whether or not the statue is a fake. In other words, if the statue turned out to be a modern replica, it appears as though it would lose its aura-related value even if it nothing else were changed. In such a case, it could look just as artful and elegant as before, but it would lack that special magnetic quality we were previously appreciating. Consequently, one might reason that the key property which generates the value we are interested in here is that which differentiates originals from fakes or replicas: the property of authenticity.

Call this claim the Authenticity Thesis. Korsmeyer also leans heavily on authenticity and related concepts during her analysis of the aura-related value in Things: In Touch with the Past and I will be drawing on many passages from this text in order to inform and support this paper's discussions. ${ }^{6}$ However, my development and eventual criticisms of the Authenticity Thesis during section 1 should not necessarily be understood as an exegesis of Korsmeyer's account. To explain: her claims, though interesting and insightful, are generally rather qualified and particularistic and she typically steers safely clear of committing herself to any concrete, universalizable principles. ${ }^{7}$ Because of this, her position is likely more defensible than the Authenticity Thesis. Nevertheless, as I hope to show by the end of this section, the concept of authenticity is ill-suited to solving the current puzzle however it is marshalled. Thus, both the Authenticity Thesis and the elements of Korsmeyer's account which center on authenticity turn out to be unhelpful at best. Granting this, it makes more sense to focus my present discussion on the Authenticity Thesis itself, rather than tackling Korsmeyer's account head-on. Doing so allows me to provide a more streamlined evaluation of the concrete and explanatorily powerful proposal that authenticity is the sole source of the valued auras in things as diverse as statues, heirlooms, and historic battlefields, without being side-tracked into ultimately irrelevant digressions concerning Korsmeyer's more nuanced claims.

\footnotetext{
6 ibid.

7 Any attempt to sum up Korsmeyer's overall thesis as a single brief assertion is likely to be contestable. Nevertheless, it seems reasonable to ascribe to her something like the following view: that authenticity or genuineness is a value-laden property (ibid., p.18) and that objects with auras are typically perceived by us to possess that property, perhaps in combination with a select variety of other important characteristics (ibid, p.161-2).
} 
The broad suggestion that authenticity is related to valued auras, as I indicated, is rather plausible prima-facie. As Korsmeyer observes, "Replicas do not draw crowds when on museum display" while originals do. ${ }^{8}$ Similarly, there is some valuable quality or qualities missing in reconstructions of certain buildings or places, such as the new Arch of Palmyra designed to replace the one demolished by ISIS in 2016, or attempts to replicate pre-historic caverns and cave-paintings for tourists, so as to protect the original sites. ${ }^{9}$ Even if these replicas were identical to the originals in all perceptible ways, a visitor might still feel like something important was missing - something that could only be experienced through an encounter with the authentic original thing. For objects such as the marble statue, we might conclude that authenticity is the key relevant variable or, in Korsmeyer's words, that "it is simply the realness of an artifact that is the target of admiration."10 (To be clear, Korsmeyer sees terms like 'real', 'authentic', and 'genuine' as related though not strictly synonymous. ${ }^{11}$ This seems correct. Yet, for the purposes of this paper, I believe the words are similar enough in meaning that it is safe to employ them interchangeably.)

Accepting the Authenticity Thesis - that authenticity is the sole property that generates the aura-related value in certain objects - provides at least one reason why we tend to see forgeries and reconstructions as lacking the same strength or range of values as possessed by originals. In fact, Korsmeyer sees authenticity or genuineness as contributing to several forms of value including scholarly value and ethical value. ${ }^{12}$ Fakes, after all, are unable to stand as historical evidence. Similarly, while we are ethically obligated to respect genuine monuments and memorials, the same obligations do not hold as strongly for replicas. Yet, it is another capacity of authentic objects altogether which Korsmeyer sees as most relevant to the aura-related value, specifically, the capacity of authentic objects to provide us with a certain kind of experience: "a shiver, a thrill, a poignant acknowledgement, a small dose of awe in the presence of the real thing." 13

In other words, authentic or genuine objects such as the marble torso offer us a kind of profound feeling or sensation. Conscious perception and proximity to an object like this is thrilling, and that explains at least partly why we value things such as the original engrossed Declaration of Independence so intensely. Unlike a mere copy, the authentic original has the capacity to provide this shiver-inducing kind of experience. Indeed, the anticipation of such an experience seems to be at least partly what it is to perceive an object as having an aura. Korsmeyer's description should feel familiar; I believe it accurately captures something of the quality of my encounter with the marble statue. Moreover, I believe it is this same kind of experience which is described in both Matthes' account of Gettysburg and Jones' account of Pech-Merle.

\footnotetext{
8 ibid., p.22.

9 ibid., p.158, 86.

10 ibid., p. 25.

11 ibid., p.11.

12 ibid., p. 126.

13 ibid., p. 28.
} 
Korsmeyer classifies this capacity as aesthetically valuable. ${ }^{14}$ This is somewhat unusual since, as she acknowledges, most aesthetic values such as beauty or grace are perceptible or directly determined by perceptible properties. ${ }^{15}$ Yet, the property of authenticity is not like this; replicas will often be perceptually identical to the original. Nevertheless, several of Korsmeyer's discussions support her classification. For instance, although authenticity is not a perceptible property, Korsmeyer argues that the thrilling experience of 'the real thing' is only possible when one directly encounters and perceives it. This is similar to the way one cannot appreciate the aesthetic beauty of a painting or song without actually looking or listening to it. ${ }^{16}$ Moreover, when we do encounter a genuine object, our knowledge that it is genuine 'penetrates' our perceptions. ${ }^{17}$ This means our ultimate experience of the object is influenced both by its perceptible properties and our awareness of its authenticity. Finally, Korsmeyer notes that the sort of phenomenal qualities involved in experiences of authentic artefacts - e.g. "thrilling, shiver producing, awesome, marvellous" - are characteristic of archetypically aesthetic experiences. ${ }^{18}$

Granting this way of further specifying the Authenticity Thesis, the valuable quality I'm targeting would turn out to be a kind of aesthetic value after all, though one distinct from qualities such as prettiness or elegance. More specifically, it would arise from the property of authenticity or genuineness, perhaps alongside other forms of moral or scholarly value, and would count as aesthetic in nature because it involves an aesthetic kind of experience: the thrill, awe, or wonder of having encountered something we know to be the real thing. One's fascination with some ancient artefact or site, therefore, could be partly explained as a result of its status as authentic and the way that can make one feel.

Unfortunately, the Authenticity Thesis is not quite right. To explain how it goes wrong, it is necessary to spell out how authenticity works more carefully. Broadly speaking, authenticity refers to the extent to which something is what it is purported or seems to be. ${ }^{19} \mathrm{~A}$ replica or a forgery fail to be authentic precisely because they seem to be something that they're not. That said, the concept of authenticity may still seem to resist any attempt to reduce it to a set of clear and precise conditions. This is partly because it appears to take on subtly different meanings in different contexts. For instance, the notion of authenticity employed when talking about a painting is different from the authenticity of Mexican cooking, or of a Rolex watch. ${ }^{20}$ It may even appear as though there are multiple ways of talking about the authenticity of one thing. For instance, to ask about the authenticity of a heritage site is sometimes a matter of composition - whether it is made from the same bricks it was originally

\footnotetext{
${ }^{14}$ ibid., p.35.

15 ibid., p.8.

16 ibid., p.32.

17 ibid., pp.54-6.

18 ibid., p.31.

${ }^{19}$ See Newman, G., and Smith, R. K., "The need to belong motivates demand for authentic objects", Cognition, 156 (2016): 129-134, p.610.

${ }^{20}$ ibid., p.609.
} 
built from. ${ }^{21}$ Alternatively, it is sometimes meant to measure the degree to which the site is still used in traditional ways by relevant cultural groups. ${ }^{22}$

Despite this, the concept of authenticity can be understood with complete clarity providing we grasp that it is a 'dimension word. ${ }^{23}$ This means something can be both inauthentic and authentic at once relative to different features. Strictly speaking then, we should always ask whether something is authentic in terms of some property or other, such as its origin, its material composition, its design, its use, its location, and so on. In fact, UNESCO lists all these properties and more as attributes through which authenticity can be expressed. ${ }^{24}$ It is true that one kind of authenticity or another may be most salient in most typical conversations, however. For instance, the authenticity of a painting is usually understood as referring to the identity of its artist, whereas the authenticity of a traditional meal typically refers to the accuracy of its ingredients and cooking methods. In cases like these, the kind of authenticity at stake can go without saying, but it remains true that authenticity and genuineness are always descriptions of some specific aspect of an object. This makes it possible to talk about 'authentic replicas', since there are two different kinds of authenticity being referenced (e.g. authenticity of origin and of style or design).

A failure to acknowledge the way authenticity works causes problems our current version of the Authenticity Theory because it means what kind of authenticity is relevant to the aura-related value is never clarified. Indeed, not all types of authenticity will always be relevant to an object's aura. For example, what delivers the aura of a typewriter owned by Hemingway is that it authentically belonged to him; whether or not it was an authentic Royal Quiet Deluxe seems irrelevant. This issue is especially serious because the relevant sort of authenticity may well change in different examples. Even more problematically, sometimes the sort of authenticity which is most relevant to the aura of the object is not the sort of authenticity which is most conventionally salient in that context. This means that, from the perspective of someone who sees authenticity as a singular property rather than a dimension word, sometimes an object can be in possession of an aura despite being perceived as inauthentic simpliciter.

For one fitting example, Korsmeyer discusses the Ark of the Covenant in Aksum. ${ }^{25}$ The original Ark reportedly contained the stone tablets upon which the ten commandments were inscribed. Nevertheless, the Ark which is presently being used in religious ceremonies is a surrogate for the real one (which is allegedly safely locked away). Despite this, Korsmeyer asserts the surrogate Ark may also possess the value we are ascribing to authenticity. This is strange; the object is a replica and

\footnotetext{
21 See ICOMOS, "International Charter for the Conservation and Restoration of Monuments and Sites", (The Venice Charter), (1964).

22 See ICOMOS, "Nara + 20: On Heritage Practices, Cultural Values, and the Concept of Authenticity", Heritage \& Society, 8 (2), (2015): 144-147.

23 Dutton, Denis, "Authenticity in Art", in Jerrold Levinson, ed., The Oxford Handbook of Aesthetics (New York: Oxford University Press, 2003).

24 See UNESCO, "Operational Guidelines for the Implementation of the World Heritage Convention", (2015), https://whc.unesco.org/en/guidelines/ p.27.

25 op. cit., p.88, 116.
} 
has not stopped being a replica. Thus, according to the kind of authenticity which is perhaps most salient, the Ark is inauthentic. To escape this seeming paradox, Korsmeyer suggests that the replica Ark could have gained the status of 'genuine' over time given its long-running role in cultural practices. I think this is quite right; over time, the replica Ark has become a genuine object of religious veneration and this new form of genuineness is relevant to its value. Nevertheless, the replica Ark is still inauthentic in the sense that it is not the original Ark. Hence, we must acknowledge the dimensionality of authenticity here. The Ark has not changed from inauthentic (simpliciter) to authentic (simpliciter). Rather, the Ark has always been inauthentic in one sense (being a replica) and became authentic in another (being an object of religious veneration).

A stronger version of the Authenticity Thesis would explicitly acknowledge the different varieties of authenticity and specify which sort of authenticity generates the aura-related value in which sort of object and why. ${ }^{26}$ Nevertheless, this stronger Authenticity Thesis would still face a serious problem: that authenticity or genuineness is not actually a value-conferring property, let alone the value-conferring property we are looking for. Earlier we observed that many objects would lose their aura-related value if they turned out to be forgeries or replicas and reasoned, on that basis, that authenticity is the property which confers the aura-related value. This leap was insufficiently justified. It is true that the concept of authenticity can be relevant to an object's value. It matters whether we have in front of us the original Ark or the replica. But it is one thing to acknowledge that something's value partly hangs on whether it is authentic in some way or other, and another thing entirely to conclude that authenticity generates that value.

Recall that some forms of authenticity can seem to convey value in certain contexts, while others do not; we value Hemingway's typewriter for being his authentic possession, while not caring whether it is an authentic Royal Quiet Deluxe. This observation conflicts with the notion that authenticity is a universally value-conferring property. However, it can be explained perfectly clearly provided, as Fredheim and Khalaf argue, we understand authenticity as a 'qualifier' of value, rather than a valuable property in its own right. ${ }^{27}$ A qualifier of value is something which can influence an object's value but cannot generate any value by itself. Another example qualifier of value they suggest is condition. A damaged vase will be less valuable (ceteris paribus) than an undamaged one. Yet, this only holds if the vase would have already been valuable in virtue of some other feature, e.g. its beauty. If the vase was worthless, on the other hand, it would still be worthless even if it was in perfect condition. Hence, condition can qualify (enhance or detract from) the value of an object but only if it already draws value from some other property; condition can never be a source of value in its own right.

\footnotetext{
26 To her credit, Korsmeyer often appears sensitive to the dimensionality of authenticity - at the very least recognising that our judgements of authenticity can be influenced by a variety of different factors depending on the context, ibid., p.11, esp. footnote 8 .

27 op. cit. p.472.
} 
Given our understanding of authenticity, we should see it as functioning similarly to condition with regard to the value of objects. To say something is authentic in some respect is simply to report that it does in fact have a property it appears to have. If that other property would be value-conferring, then authenticity becomes relevant to value, yet it does not confer any of the value itself. For example, the authenticity of an apparent Picasso painting is relevant to its value, not because the authenticity would generate value in its own right, but because being painted by Picasso would generate value and authenticity here simply confirms that the painting was truly painted by Picasso. On the other hand, if a painting was confirmed to be an authentic work of $\mathrm{X}$, that would not be relevant to its value if $\mathrm{X}$ were just some nobody. In short, while the aura-related value might disappear from an object if it were not authentic in certain key respects, that does not mean the authenticity generates the aura. Rather, authenticity merely indicates the presence of the property which aura does arise from, whatever that property is. It confirms the presence of some other value-conferring property (and thereby qualifies the object's value) but does not confer any value itself.

This can be seen in all types of value which Korsmeyer sees as connected to authenticity, not just the aesthetic, aura-related value. For instance, what actually confers scholarly value is not an object's authenticity but some other property, say, the fact that it evidences the use of certain tools in its construction. A judgement of 'authenticity' merely signals that it does hold this other value-conferring property, and its apparent presence is not illusory. Similarly, what gives an object ethical value is, for instance, that it commemorates a particular tragedy. A judgement of authenticity confirms this is true, but authenticity is not the source of that ethical value any more than the value of an authentic bucket of motor oil is conferred by its 'authenticity'.

To conclude this section, a closer examination of the concept of authenticity has allowed us to identify where the Authenticity Thesis goes awry. The key claim was that the property we value in objects with auras is their authenticity itself. Yet, as we should now see, this isn't right. For starters, every object is authentic in at least some respects; even forgeries and copies are really the thing that they are. Furthermore, even if we specified the relevant variety of authenticity in some particular case, it still wouldn't follow that this property is what we are admiring in the object because authenticity is only a value qualifier. It is true that we value Hemingway's genuine typewriter and would not value a fake in the same way, but it is the property 'belonged to Hemingway' (or something like it) which confers the value here; the label 'genuine' merely indicates that this valuable property is present, as it appears to be. ${ }^{28}$ The challenge now is to identify the property, which is common to objects

\footnotetext{
${ }^{28}$ Korsmeyer's discussions sometimes indicate a sympathy to this analysis. For instance, she occasionally seems to suggest that judgements of authenticity (which she sees as essentially evaluative) are only merited when the object is already significant or valuable in some way (op. cit., p.161). This could align with the view that judgements of authenticity, at best, merely identify or confirm the presence of the true value-conferring properties. Nevertheless, other passages from Korsmeyer - e.g. "realness... is the target of admiration" (ibid., p.25), and "genuineness is... a general value property with an aesthetic aspect" (ibid., p.18) - appear to conflict with this reading.
} 
with auras and often correlates with conventional judgements of authenticity, that actually confers the value we're interested in.

\section{Contact Value}

Some of Korsmeyer's other discussions can point us in the right direction. Recall, it was suggested earlier that we need to encounter an object with our senses in order to appreciate its aura. The sense which Korsmeyer sees as most central to this is touch. She argues that, when we stand before an object like the marble statue, it is touch (or the knowledge that one is within touching-distance) which "summons the awareness" that we are in the presence of something authentic and prompts the valuable aesthetic experience. $^{29}$

I agree with Korsmeyer that physical proximity and touch are important for us to enjoy the aura of certain objects. Moreover, Korsmeyer's discussion on this topic also brings us closer to identifying the true source of the aura-related value. Specifically, she notes that "the act of touching possesses a kind of transitivity, that by literally being in contact with an object, one establishes or retains a sort of remote contact with others who have touched the same thing." 30 This is part of the reason encounters with certain objects can be so thrilling. By holding the marble statue, a kind of connection is created between myself and the artist who originally carved it. Korsmeyer notes that this phenomenon is particularly relevant to objects "that were used (and touched) by certain people and under special circumstances, such as the paper on which Lincoln wrote the Gettysburg address or a violin, now silent, once played by Paganini." 31

This kind of touch-based connectivity seems like a better candidate for the valuegenerating property we are seeking. Yet, basing our account purely on the transitivity of touch would be too restrictive. For instance, Korsmeyer speaks of individuals rushing to collect fragments of a meteor which fell to Earth over Chelyabinsk. ${ }^{32}$ I agree that a meteor fragment could possess a valued aura, and yet there can be no transitivity of touch here precisely because it has never been touched before. Korsmeyer also mentions the power we can feel when listening to old records, hearing the voices of long-dead singers. ${ }^{33}$ In such cases, we may also experience something like an aura but, again, it is difficult to explain this in terms of transitivity of touch.

Matthes offers a broader and more promising suggestion: what we value here is not transitivity of touch in particular, but rather any kind of experience of the past. ${ }^{34}$ Matthes expresses his theory in the language of time-travel. Specifically, he notes that, while travelling to the past is impossible, when we touch an ancient object,

\footnotetext{
29 ibid., p.162.

30 ibid., p.61.

31 ibid., p.163.

32 ibid., p. 28.

33 ibid., pp.16-7.

34 op. cit., p.65
} 
we are engaging with an object which has, essentially, time-travelled from the past to the present moment. This time-travelling ability of historic objects allows us to experience history directly, in a way no history book or documentary can provide. At Gettysburg, for instance, one can tread on the very ground used for the battle and see bullet holes still preserved through the town. What is valuable about this, Matthes stresses, is that we are offered "a significant connection with a significant past" and one we cannot get in any other way. ${ }^{35}$

The notion of a connection to the past, is plausibly what lies at the heart of the aura-related value of the marble statue, Gettysburg, and many other things. Yet, Matthes' theory, with its emphasis on time-travel and history, is also overly narrow for our purposes. Two observations allow us to break free of the focus on significant history. First, even new things can possess auras. For instance, if someone received a hand-forged engagement ring from their partner, they may perceive it to hold the aura-related value and in virtue of a connection it offers them. However, the connection would not be to the past but to the partner that created it, who exists in the present. Second, as this example also shows, the aura-related value is ultimately a personal kind of value. The only people who would feel the valued aura of the engagement ring are those who desire a connection to the person who made it. The same is true of historical connections. Indeed, it is possible to interpret Matthes as suggesting that what we care about is not a connection to events or people which are historically significant, but rather to events or people which are already personally significant to me (or which become so upon my experiencing the relevant connection). To support this reading, we can note Matthes' suggestion that visiting a personally significant "childhood haunt" could hold broadly the same form of value as a visit to Gettysburg. ${ }^{36}$

In light of these observations, I believe there is a more fundamental kind of valuation going on, one with a broader scope and greater explanatory power. Specifically, where Matthes focuses on the value objects possess in virtue of their connection to the past, it strikes me that objects may hold the same general kind of value through connecting us to anything, provided we appreciate that connection. In other words, one property we value in certain objects or sites is their capacity to offer us a desired sort of metaphorical or indirect contact with something else. The thing connected-to need not be a historically significant event or person. Rather, it could be almost anything from any time-period, whether a living creature, inanimate object, event, achievement, or even an immaterial concept or ideal. It is this 'contact value', which I believe explains the aura of certain heritage artefacts and historic sites, but also things like the auctioned-off possessions of celebrities, holiday souvenirs, and ticket-stubs. These things are often superficially worthless, yet we treasure them because of the people, events, and things they can (metaphorically) put us in touch with.

Two important questions now need to be answered: how do objects 'put us in touch' with other entities, and why do we find that capacity valuable? I will begin

\footnotetext{
35 ibid., p.64.

36 ibid.
} 
with the latter, though the explanation I offer is perhaps unsatisfyingly simple: we (rightly) find value in objects with certain connections to certain entities because we like being connected to those entities in those ways. ${ }^{37}$ There are many reasons a person might desire a particular connection, whether grounded in universal human nature or personal idiosyncrasy. Indeed, I will indicate several throughout the rest of this paper. However, I will largely focus on one common and straightforward motivation: we desire the connection an object offers us to $\mathrm{X}$ because $\mathrm{X}$ is something we already feel some positive attitude towards, such as admiration, affection, or fascination. To explain: typically, when we feel this way about something, we desire to engage with it, and we prefer more intimate or immersive forms of engagement to shallower ones. ${ }^{38}$ For instance, we'd typically prefer to have lunch with a friend than chat to them on the phone. We'd rather shake a celebrity's hand than merely spot them across the street. We'd rather visit interesting places in person than see them in pictures. Moreover, this predilection seems to persist independently of any instrumental benefits that might accrue from the more intimate forms of engagement. Getting to shake a celebrity's hand won't really do anything for us, and yet we desire it all the same. To reiterate, there seems to be a general preference here: we desire encounters with entities we admire. We desire them for their own sake and, ceteris paribus, the more intimate or immersive the encounter the better.

That acknowledged, if we also grant that objects can put us in touch with admired entities, it follows that this could confer a degree of value on those objects. Naturally, the indirect contact offered by an object won't typically be as desirable to us as a direct encounter with the admired entity itself, but it will still count for something. An autograph isn't as good as an in-person meeting, after all, but can still be cherished because of the relation it possesses to the autograph-signer. As noted, this is just one reason we can value the connections offered to us by certain objects. Later on, I will return to it, and discuss a few others. For now, it is more pressing to spell out the notion of 'indirect contact' employed above. It is common to suggest that objects can 'connect' us to other things, particularly the past. ${ }^{39}$ But what is the nature of this connection?

Answering this is difficult. At the widest scope, we ought to be looking at the relational properties of the object in question. Yet not every relational property is suitable to confer contact value. Perhaps a rock weighs the same as Lincoln, but the relational property 'weighs the same as' is insufficient to grant the rock any kind valuable aura. Whatever connection this relation establishes, it is evidently not one we appreciate in the manner at hand. Several kinds of relational property do consistently seem suitable, however. In this paper I will focus on three: causal relations, teleological relations, and relations of symbolic representation. Precisely what these

\footnotetext{
37 Here I grant, as a general rule, that something is pro tanto valuable for us if it has a property we like or desire, and there are no relevant defeaters (such as our being brainwashed to like it or being tricked about the benefits of that property etc.).

38 What kind of engagement counts as most immersive will likely differ in each case, depending upon the nature of the thing and our reasons for valuing it - for places or artworks it will likely involve visiting or seeing in-person, whilst for tools it may involve physically holding or using.

39 See, e.g., Korsmeyer, ibid., p.28 and Matthes, op. cit., p.62.
} 
kinds of relation have in common is unclear, but it suffices to say that they reliably seem to establish a full-blooded kind of connection of the sort that can generate contact value. ${ }^{40}$

Causal contact is perhaps the clearest category and the one I'll discuss most. An object is causally connected to anything it was affected by (e.g. the agents who produced it, changed it, or moved it) and anything it played a role in affecting. As a rule of thumb, two things will be related in this way when they have directly physically interacted with each other or, to a weaker extent, when there is a close chain of such interactions between them. However, even if a causal interaction did not produce a lasting effect, it can still count here. Hence, merely touching an object someone else touched or standing in the spot they stood could also be included in this category of contact. It is in this sense that a building connects us to both its previous inhabitants and its original builders, and an artist's paintbrush connects us both to the artist and the works it helped produce. Reflecting on these examples, is clear this sort of connection can confer a valued aura; we would indeed value Picasso's paintbrush and because it was once held by him. Objects which relate us to some $\mathrm{X}$ in virtue of being a part of $X$ themselves also fall into this group. Korsmeyer gives two examples which gain contact value in this way: a splinter of wood from the Titanic and a traditional 'mourning brooch' made with the departed person's hair. ${ }^{41}$

The next form of contact is teleological contact. Like causal contact, this sort of relation can also be constituted in a variety of ways although, in this case, each relation must involve some form of intentionality or purposeful use. For instance, an object will be teleologically connected to the people who used it for some goal or project. It can also be teleologically connected to the products or achievements of the purposes it was designed or used for. As such, Michelangelo's chisel would be teleologically (and causally) related both to Michelangelo and the Pietà, and a bookshelf might teleologically connect me to my father if it was his creation. Importantly, and unlike causal contact, objects can be teleologically related to things even if they never physically interacted with one another, even indirectly. A work of architecture will be teleologically related to its original blueprint, for example, even if that blueprint never left the architect's remote office. This is especially true when the product or achievement an object is teleologically related to is not also a single physical thing, but something more complex, abstract, or drawn-out. For instance, the pen which signed the Emancipation Proclamation connects us to that piece of legislation's admirable (ongoing) impacts. Again, reflecting on these examples seems to confirm that all these sorts of teleological relation can confer a substantial aura, i.e. contact value, to objects in the right contexts.

Finally, relations of symbolic representation are constituted between an object and the things it represents, whether through visual resemblance or other more abstract means of signification. This means a portrait could connect us both to the

\footnotetext{
${ }_{40}$ It may be relevant that causal, teleological, and symbolic relations could each be described as meaningful connections whereas connections like 'weighs the same as' are not. For more on meanings see Thomas, Joshua Lewis, "Meaningfulness as Sensefulness", Philosophia, 47 (2019): 1555-1577, and 'When does Something 'Belong' to a Culture?', British Journal of Aesthetics, (2021), forthcoming.

41 op. cit., pp.65-7.
} 
person it depicts, and the ideals or concepts it evokes. Both kinds of connection can generate the aura-related value. A parent might value a sketch drawn by their child not just because it represents their family but because, to them, the sketch also symbolizes something like the child's love. Similarly, the engagement ring mentioned earlier could also be valued for symbolizing the partner's commitment. Symbolic meaning can be personal like this, but it can also be upheld by shared convention. We collectively agree that the rainbow flag represents LGBTQ pride, for instance. In light of this, those who admire LGBTQ pride may value the flag for putting them 'in touch' with this ideal. Equally, a patriot might value their country's flag because it connects them to the nation they admire. ${ }^{42}$

The relationships just outlined are a heterogenous lot. Yet, there is a common perception that objects can put us in a desirable kind of contact with the things they are related to in these ways. Nevertheless, does it really make sense to suggest we value Lincoln's pen for 'connecting us' to the achievement of ending slavery, or the rainbow flag for 'putting us in touch' with the ideal of LGBTQ pride? As noted, we cannot engage with goals or ideals like these directly since they are too wideranging, immaterial, or abstract. Thus, it may sound strange to suggest that objects can gain any value by connecting us to them. However, this is where contact value is most significant. It is because such things are impossible to engage with directly that the indirect forms of engagement offered by certain objects becomes valuable to us. We cannot gaze upon LGBTQ pride, but we can look at a flag which puts us in touch with the concept. We cannot hold our chess tournament victory or shake hands with early suffragettes, but we can feel the weight of the trophy we won or rest a hand on a stone monument. In short, if we admire and want to engage with particular concepts, events, or movements, yet have no way to do so directly, we must instead find objects that can connect us to them via their relations, such as flags, trophies, and memorials.

Indeed, the inability to access more direct forms of engagement is presumably what motivates our appreciation for any contact valuable object. If I'm correct that objects with contact value are cherished because of their capacity to put us in touch with certain events, concepts, or individuals, it stands to reason that this feature will primarily gain its appeal when those things are difficult or impossible to engage with in their own right. For instance, we might value a relic from a hobby we no longer have time for, or a trinket given to us by a friend who now lives on the other side of the world. But consider how odd it would be to focus our valuing attitudes entirely on the trinket during occasions when the friend has come to visit. This indicates one reason why we might typically value old objects more than new ones; when a person or event exists only in the past, direct contact is impossible. Thus, the aged objects which put us in contact with them can become valuable as a result. As Matthes puts it, it is our inability to visit the past which makes engaging with objects from the past so special. If we could travel in time, such objects would lose much of their

$\overline{42}$ See Sneddon, Andrew, "Symbolic Value”, Journal of Value Inquiry, 50 (2), (2016): 395-413. 
appeal. ${ }^{43}$ This also explains one reason the possessions or creations of individuals typically become more valuable after they have died; generally, the indirect contact promised by certain objects becomes significant to the extent direct contact is, for whatever reason, beyond our reach.

An interesting question is whether we can appreciate contact with some place or time-period merely because it is inaccessible to us (rather than, say, because we independently admire what is connected to). As I noted, there are a variety of reasons someone might value a connection, and this one seems plausible. For instance, if inaccessibility alone is enough to generate a fascination in something, then one might reasonably value objects connected to it. Granting this, an object may gain contact value merely in virtue of its age, though only for people with a desire to be put in contact with 'the past' simpliciter. ${ }^{44}$ The marble statue described earlier may itself be valuable in this sense, especially since we know so little about it. Nevertheless, we can assume, for instance, that its sculptor was talented - giving us cause to admire them. Moreover, the sculptor seems to share our appreciation for beauty despite living incredibly long ago in very different circumstances. Connections like this, across large distances in time or space, can remind us of our shared humanity, and make us feel more at home in the world. Thus, one might find additional reasons to value the contact offered by the statue.

\section{Possible Objections}

To reiterate, I have argued several points: first, objects can offer us indirect forms of contact to the people, events, and concepts they are connected to via certain kinds of (e.g. causal, teleological, and symbolic) relational properties. Second, for the specific people who appreciate those connections, the objects will possess what I've called 'contact value'. Third, while there are many reasons a person might appreciate a specific connection, one common motivation is our general preference to engage with things which we admire. Here we typically prefer more intimate forms of engagement, but the indirect forms of contact provided by certain objects are also somewhat desirable. In short, I believe that the aura-related value this paper has been examining is constituted by the capacity of objects to put us 'in touch' with various things in ways we like. ${ }^{45}$

Granting this, when a replica lacks the valued aura an original possesses, the value-conferring property which it is missing will not be authenticity or genuineness strictly speaking. Rather, the relevant difference between the original and the copy will be that only the original has certain important relational properties, such as 'being created by person $\mathrm{X}$ ' or 'being used in historic event $\mathrm{Y}$ '. In many cases,

\footnotetext{
43 op. cit., p.62.

44 An analogous thought may explain why we value meteorites and moon rocks, as Matthes notes, ibid., p.62.

${ }^{45}$ Korsmeyer argued genuineness was related to multiple forms of value (op. cit., p.126). I agree to a structurally similar point; the relational properties relevant to contact value might also contribute to, say, scholarly value or ethical value in some cases. However, I will maintain my focus on contact value here the value which arises in virtue of people's appreciation of the relations themselves.
} 
conventional judgements of authenticity will track the presence of any important relational properties, such as when talking about genuine or forged artworks. However, other cases are less straightforward. For instance, the replica Ark of the Covenant has been used in religious practices for a long time, giving it many causal, teleological, and symbolic connections, which certain people may value. As such, it possesses contact value for them despite being a replica and hence inauthentic in one salient sense. Korsmeyer was right to acknowledge the significance of the Ark's long-running religious role then, but its significance is best explained in terms of valued connections not by its downwind effect on the authenticity of the object.

Korsmeyer also argued that the aura-related value was aesthetic in nature. The same may be true for contact value. Certainly, encounters with contact valuable objects can produce the thrilling experience Korsmeyer described. Nevertheless, I am tempted to believe the capacity to produce that kind of experience does not exhaust the worth of contact value, but is rather an additional benefit to its core (perhaps sui generis) worth. Indeed, as I will argue later, I believe objects can hold contact value for a person even if they never succeed in provoking anything like that kind of experience. If so, contact value will not count as aesthetic in nature for those who view aesthetic value as a feature of experiences - the position I am most partial to. That said, my account of contact value is also compatible with other positions on aesthetic value as well.

My remaining space is best devoted to responding to a few important challenges to the notion of contact value. One possible objection centers on the role symbolic representation has in my theory. Specifically, if I grant mere symbolism the power I seem to, it may appear that a huge amount of contact value could be attributed to anything simply by pointing at it and designating that it signifies whatever valued entity we choose. There is a sense in which this is possible, but with some caveats which disarm the issue. First, symbolic meaning isn't always something that we can simply conjure up. Even if one chooses to treat some rock as symbolizing, say, Florence Nightingale, others have little reason to see it this way, and hence any value which might be conferred to the rock based on this will be greatly restricted; it will have contact value for that person, but no one else. Furthermore, symbolic meanings of the kind that matter to contact value need to be felt as much as cognitively believed, so simply stipulating a signification often won't be enough. Although, an attempt to lodge some symbolic meaning in an object will do better when there are certain features of that object which make it well-suited to symbolically representing what it is supposed to, such as a physical resemblance.

Nevertheless, if an entire population came to believe that some rock symbolically represented Nightingale - as they might if the rock was carved in her likeness and given a named plaque - then this monument would seem to gain some genuine contact value as a result. We can accept this much. However, it could also be argued that the contact value here would be weaker than the contact value possessed by, say, Nightingale's famous lamp or her journal. I claimed earlier that we typically prefer more intimate forms of connection to the things we admire. Accepting this, 
it follows that objects which are valued for their connections will be more valuable to us when those connections are themselves stronger and more intimate. ${ }^{46}$ For instance, a typewriter Hemingway used to write a whole novel will have a stronger connection to him than one he only used to write a letter, and will be more highly prized by his fans as a result. Equally, connections of symbolic representation may generally seem less intimate than others, and hence less conferring of contact value. The lamp and journal were physically used by Nightingale, whereas the statue's relationship to her is far more abstract and tenuous. Thus, we may think the former objects hold greater contact value. (Of course, this may be reversed in other cases. Portraits or sculptures can often capture the personality of their subject in remarkable ways and, as such, offer connections which feel even more intimate than those offered by the subject's physical possessions.)

What about objects whose connections to loved or admired things do not appear to give us reason to value them? Imagine a child was murdered and the parents were later presented with the murder weapon. According to my earlier arguments, if a person loves something, we should expect them to value any object that connects them to it. Nevertheless, it would seem strange for the parents to value this weapon because it puts them in touch with their beloved child. Indeed, we should fall back to my first premise: contact value only exists where objects offer desired connections. This means it is not always sufficient that an object merely connects us to an admired entity, it needs to connect us in a way we appreciate. In this case, the weapon is causally and teleologically related to the child, but the relations are extremely dark and destructive in nature. Thus, granting the parents would not like such contact, they would find no contact value in the object. Equally, if a caricature symbolically represents someone in an offensive and derisive manner, this could undermine any contact value it might have otherwise obtained.

To reiterate, the specific nature of the connections offered by an object can determine whether or not they will be desired, and hence whether they function as a source of contact value. We can also reason that objects which offer actively unwelcome connections (e.g. relating detrimentally to things we admire or positively to things we despise), would hold a kind of contact disvalue. Indeed, Matthes describes the sense of "revulsion" we can feel "when confronted by objects significant for their connection with a history of oppression and violence." ${ }^{47}$ Psychological experiments support this: as one example, participants reported positive feelings when imagining wearing a sweater belonging to an admired figure but displeasure at the prospect of wearing an enemy's sweater. ${ }^{48}$ Additionally, in a result which supports

\footnotetext{
${ }^{46}$ It also suggests that we should prefer closer forms of engagement with contact valuable objects themselves. Experimental data seems to support this: When photographed with their favourite possessions, participants whose attachment was based on "person or maker-based" reasons were more likely to "touch or embrace" or at least pose physically closer to the object, than those whose attachment was based on other factors such as practical function. See Wallendorf, Melanie, and Arnould, Eric J., "My Favorite Things': A Cross-Cultural Inquiry into Object Attachment, Possessiveness, and Social Linkage," Journal of Consumer Research, 14 (1988): 531-547, p.542.

47 op. cit., p.62.

${ }^{48}$ See Nemeroff, C. J., and Rozin, P., "The contagion concept in adult thinking in the United States: Transmission of germs and of interpersonal influence", Ethos: Journal of the Society for Psychological Anthropology, 22 (1994): 158-86, p.170.
} 
my above suggestions about the relative power of symbolism versus other relations, participants were found to be actively averse to a new copy of Mein Kampf but were even more averse to a dictionary they believed to be owned by Hitler. ${ }^{49}$

These cases are clear-cut, but more ambiguous or complex examples are also possible. What if, in the earlier example, the murder weapon was the only connection the parents had to their deceased child? In such a case, its possible (though difficult) to imagine them feeling some appreciation of it - the desire to have any kind of connection to their child outweighing the fact that this particular connection is rather unpleasant. Similarly, one might have cause to see both contact value and disvalue a single object. The gun which Wilkes Booth used to assassinate Lincoln, for instance, might be valued as a connection to a historically significant event, but disvalued for its destructive relationship to an admired person. For those with both an interest in historic events and an admiration for Lincoln, we can expect encountering the gun to be an intense but mixed experience. The important upshot is this: which objects hold contact value or disvalue and why will vary from person to person based on their interests and the connections they desire. ${ }^{50}$

It also makes sense to think contact value could be influenced by which aspects of the connected-to entity an object most closely puts us in touch with. For instance, the more intimately an object relates to an entity's most admired features, the more contact value we should typically expect to see in that object. This would explain why we value the Gettysburg address more than Lincoln's socks, as Matthes points out, ${ }^{51}$ or why we'd value Hemingway's typewriter more than his toothbrush. Notions like the transitivity of touch or the idea of these objects time-travelling from the past cannot account for this difference by themselves. Yet we can account for it with reference to contact value, since it is sensitive to how much we appreciate the specific connections on offer. As such, Hemingway's typewriter would be more valuable because it relates us to the aspects of his life to which we most want to be connected (assuming we're fans of Hemingway qua writer).

What if a person is mistaken about the relational properties an object possesses? A lamp owned by Nightingale may be immensely valuable because of its relationship to her, but what about a lamp that is falsely attributed to her? Another way of framing the question is this: does the contact value inherent in certain objects depend on their actual connections or only on the connections we perceive them to

\footnotetext{
49 See Fedotova, N. and Rozin, P., "Contamination, Association, or Social Communication: An Examination of Alternative Accounts for Contagion Effects", Judgment and Decision Making, 13 (2), (2018): 150-162.

${ }^{50}$ It is worth acknowledging that objects with contact disvalue can still be valued overall for other reasons. Auschwitz holds a great deal of the contact disvalue in virtue of its purpose and its causal impact. Yet it has other compensatory values, such as scholarly value for historians, and ethical value in its function as a memorial for the victims of the holocaust and as a warning to future nations. Compare the houses of murderers Huntley and West, which also had considerable contact disvalue but little or no redeeming features, and were consequently demolished as emphatically as possible in order to "expunge the sense of evil linked to the place", Coughlan, Sean, "What happens to the houses of horror?", $B B C$ News Online, (2004), http://news.bbc.co.uk/1/hi/magazine/3593137.stm.

51 See Matthes, Erich Hatala, "Authenticity and the aesthetic experience of history", Analysis, 78 (4), (2018): 649-657, p.652.
} 
have? The former seems correct to me; however we characterize contact value, it appears to be the true relational properties which primarily determine its presence. Although a fake lamp might provide certain benefits to me in virtue of the connections I (and others) falsely perceive it as having, these perceptions are not sufficient for contact value. This value can only be constituted by an actual connection forged between the object and the entities it is related to. I would have been made better off by engaging with an object that genuinely put me in a desired kind of contact with Nightingale, but the fake lamp only creates the illusion of that contact. In short, just as the value of friendship is grounded on real friendship and would be absent if one's 'friend' secretly despised one, the contact value of my lamp is grounded on its real connections. I may think the fake possesses a certain kind of contact value, but I would be wrong. ${ }^{52}$

That said, symbolic representation will operate slightly differently to other relational properties in this regard. As explained earlier, if I came to believe that, say, a traffic-control bollard was actually an obelisk and symbolic of some valued person, then it would actually have that symbolic meaning at least to me. Therefore, it may also gain some very small amount of contact value in virtue of the (extremely limited in scope) relationship between the object and the figure which I have willed into existence. Nevertheless, it will certainly not have the same value it would have possessed were everyone to perceive its symbolic meaning in this way. As such, if I believe that everyone shares my belief, and that the bollard possesses a great deal of contact value, I will be mistaken. Beliefs about contact value based on perceived symbolic meanings are slightly resistant to error, therefore, but only very slightly.

What of the opposing circumstance, for example, where I own a pen but am unaware that it was once used by Lincoln, or wear a watch in total ignorance of the fact it belonged to my dear grandfather? Is an awareness of something's true relations a necessary requirement for contact value to obtain? I think not. Naturally, a person won't consciously be thrilled by an object if they remain unaware of its significant relational properties, but these properties seem sufficient to establish at least some degree of contact value, nonetheless. Intuitively, I would indeed be better off in the scenario where I own Lincoln's pen and wear my grandfather's watch than the scenario where these are merely modern fabrications. The facts of the case - including the relationship between these people and the objects and the fact I would appreciate these connections were I aware of them - make it such that it is good for me to possess the objects, whether or not I know the truth.

\footnotetext{
52 This serves to distinguish my theory from the superficially similar notion of 'associative value' where an object allegedly derives value merely from being mentally associated with something else. See UNESCO, "International Coalition of Sites of Conscience: Interpretation of Sites of Memory", (2018), https://whc.unesco.org/en/activities/933/, art.32, 52. Because associative value is seemingly determined by perceived associations rather than actual connections, it fails to discriminate between the value of reals and fakes (which can have precisely the same associations to us). It also fails to discriminate between full-blooded connections (such as causal, teleological, and symbolic relations) and other relational properties like 'weighs the same as', which may be enough to establish an 'association' in our mind but are unsuitable for conferring any valued aura. At best, we can charitably interpret associative value as being grounded in an object's capacity to remind us of something else, but this is a very different form of value than the one targeted here.
} 
To further prompt this intuition, consider the following case: my acquaintance has a similar-looking watch to mine and we accidentally swap them one day. Now the watch which belonged to my grandfather, which I would cherish above most other things were I to discover its true nature, will go home with him and I may never see it again. Hopefully this should strike the reader as a minor tragedy; even though I may never suffer any negative experiences because of it, it seems bad for me. If this is true, it supports my claim that the contact value which I would recognize in the watch were I to know the truth still exists, even when I am ignorant. I would have lost something of great value to me, whether I was aware of that or not.

One final point: I have argued that perceived but false relations are insufficient to generate contact value. What does this entail about objects or sites which are valued on the basis of spiritual beliefs? If some group feels that a rock formation has immense contact value on the basis of a shared belief that it was created by their deity, and this belief is mistaken, does that mean the rock-formation is actually worthless? The answer is no, for a couple of reasons. First, we should remember that there are many other forms of value besides contact value, several of which may be relevant here. For instance, the formation may serve to memorialize historical events, rituals, and achievements, and by protecting it, one may also honor the past human beings who labored to preserve it, granting the formation both commemorative and ethical value. Besides this, the formation may also positively contribute to feelings of belonging and collective identity for those who care about it, ${ }^{53}$ consequently improving both their self-esteem and sense of meaning in life. ${ }^{54}$

Moreover, because of these various beneficial effects and connections, the formation could also gain some genuine contact value in virtue of the real and desirable links it affords us to, e.g., the traditions it has played a role in, the past generations who protected it, and the positive impact it had on their wellbeing. ${ }^{55}$ Naturally, this value won't be as grand as it would have been were the formation created by an actual deity, but it would still count for something. Moreover, as noted above, beliefs about contact value based on perceptions of symbolic representation are somewhat resistant to error. Thus, to the extent the contact value of the rock formation (or anything like it) is generated through beliefs about the values or ideals it symbolizes, and to the extent this symbolism is widely perceived, the rock formation will gain additional contact value. In many cases then, objects and sites which appear to be primarily significant because of a (presumably) false spiritual connections can still obtain many forms of value, including contact value, particularly when they are the focus of certain symbolic meanings or at the heart of long-running practices.

\footnotetext{
53 See e.g. Jones, Siân and Steven Leech, "Valuing the Historic Environment: A Critical Review of Existing Approaches to Social Value", Report for the AHRC Cultural Value Project, (2015), and Kenworthy, Elizabeth, "Identity and Place: The testament of designated heritage in Hong Kong", in Laurjane Smith (ed.), Cultural Heritage: Critical Concepts in Media and Cultural Studies, Vol IV, (2006): 285208, p. 285.

54 Lambert, Nathaniel M., Stillman, Tyler F., Hicks, Joshua A., Kamble, Shanmukh, Baumeister, Roy F., and Fincham, Frank D., "To Belong Is to Matter: Sense of Belonging Enhances Meaning in Life", Personality and Social Psychology Bulletin, 39 (11), (2013): 1418-1427, p.1418.

55 Korsmeyer appears to agree with this (op. cit., p.88-9). Indeed, the value of the formation will be similar to the value held by the replica Ark of the Covenant; despite being non-genuine in one sense, both are extendedly tied to religious and cultural practices in ways a person might appreciate.
} 


\section{Conclusion}

At the start of this paper I identified a certain kind of valuable aura-like quality which appears to surround many objects, including historic sites, cultural heritage artefacts, family heirlooms, and even moon rocks. I have argued that this valuable quality is not best explained as arising from the genuineness of these objects - though it is often lacking from replicas and forgeries. Instead, drawing on insights from Korsmeyer and Matthes, I have argued that these objects are valuable in virtue of the desirable connections they offer us to other things, including people (living or dead), places, events, achievements, and concepts. This capacity, which I called 'contact value', is most significant when the entities connected to are too abstract, complex, or long ranging for us to engage with directly, or when they have disappeared into the distant past. This is why the value is often perceived in historic cultural heritage like cave-paintings or battlegrounds, but also in more recent and mundane things like souvenirs and ticket stubs which connect us to cherished events in our lives that we cannot return to. There is certainly a great deal more work to be done on this topic, but I hope to have done enough to defend contact value as a genuine mode of valuation and demonstrate how widespread and influential it can be.

Acknowledgements This paper was developed during my time as a postdoctoral research fellow in the Heritage in War project, funded by the Arts and Humanities Research Council (UK), grant number AH/ P015077/1. There are various people I would like to thank for their role in shaping my ideas including the Heritage in War core research group, the attendees of the Society for Applied Philosophy conference in 2019, the members of the Open University's Philosophy Department, and two anonymous reviewers of this journal. I would also like to show gratitude for the financial support of the Society for Applied Philosophy, which allowed me to complete this paper.

Open Access This article is licensed under a Creative Commons Attribution 4.0 International License, which permits use, sharing, adaptation, distribution and reproduction in any medium or format, as long as you give appropriate credit to the original author(s) and the source, provide a link to the Creative Commons licence, and indicate if changes were made. The images or other third party material in this article are included in the article's Creative Commons licence, unless indicated otherwise in a credit line to the material. If material is not included in the article's Creative Commons licence and your intended use is not permitted by statutory regulation or exceeds the permitted use, you will need to obtain permission directly from the copyright holder. To view a copy of this licence, visit http://creativecommons.org/licen ses/by/4.0/.

Publisher's Note Springer Nature remains neutral with regard to jurisdictional claims in published maps and institutional affiliations. 